\author{
MAREK RADOMSKI \\ Uniwersytet Marii Curie-Skłodowskiej w Lublinie \\ Katedra Językoznawstwa Angielskiego i Ogólnego
}

ORCID: 0000-0002-2512-5833

\title{
Komponent fonologiczny języka polskiego jako struktura rdzeń-peryferie na przykładzie akcentu wyrazowego w galicyzmach
}

\begin{abstract}
A b s t r a kt: Tematem artykułu jest adaptacja akcentu wyrazowego w galicyzmach w języku polskim. Przedstawione dane pokazują, że omawiane zapożyczenia można podzielić na dwie kategorie pod względem umiejscowienia akcentu. $Z$ jednej strony istnieją wyrazy z akcentem paroksytonicznym, zgodne $\mathrm{z}$ rodzimymi regułami akcentowania. Z drugiej strony są takie wyrazy, które zachowują pierwotny akcent oksytoniczny, naruszając te zasady. Proponowana analiza formalna tego zjawiska w ramach teorii optymalności opiera się na założeniu wywiedzionym z prac Itô i Mestera (1995, 1999, 2001), zgodnie z którym systemy fonologiczne języków naturalnych mają strukturę rdzeń-peryferie. Galicyzmy z akcentem paroksytonicznym zostały przyporządkowane do rdzenia, natomiast te $\mathrm{z}$ akcentem oksytonicznym do sfery peryferyjnej. W każdej z tych warstw obowiązują odmienne rankingi ograniczeń fonologicznych, czego wynikiem jest rozbieżność akcentowania w obu grupach zapożyczeń.
\end{abstract}

Słow a klucze: galicyzmy; fonologia zapożyczeń; akcent wyrazowy; teoria optymalności

\section{Wprowadzenie}

W języku polskim galicyzmy, czyli zapożyczenia z języka francuskiego, stanowią istotną grupę wyrazów obcego pochodzenia. Jak zauważa Bochnako- 
wa (2012), są one głównie rezultatem polsko-francuskich kontaktów kulturowych, z jednej strony związanych z wydarzeniami o charakterze politycznym (np. polsko-francuskimi małżeństwami dynastycznymi), a z drugiej - z silnym wpływem kulturowym Francji w XVII i XVIII w. Galicyzmy w polszczyźnie stały się przedmiotem licznych opracowań i analiz językoznawczych (np. Bochnakowa 2009, 2012; Borys 2000; Porayski-Pomsta 2007, 2011; Rybicka 1989; Sypnicki 1983; Tombińska 1998; Walczak 1992a, 1992b), koncentrujących się na różnych aspektach takich zapożyczeń, począwszy od ich etymologii do procesów asymilacyjnych, którym podlegają na płaszczyźnie graficznej, fonetyczno-fonologicznej, morfologicznej i semantycznej. Należy jednak zauważyć, że pomimo istnienia tak bogatej literatury przedmiotu kwestie związane z fonetyczno-fonologiczną adaptacją galicyzmów w polszczyźnie nie doczekały się kompleksowego omówienia, szczególnie w zakresie formalnej analizy w ramach teoretycznych podejść fonologicznych.

Fonetyczno-fonologiczna asymilacja zapożyczeń jest złożonym procesem, na który wpływa wiele czynników zarówno wewnątrzjęzykowych, jak i pozajęzykowych (Szpyra-Kozłowska 2016a, 2016b; Radomski 2019). Nie dziwi zatem istnienie wielu modeli teoretycznych, które wyjaśniają mechanizmy tego zjawiska, przyjmujących różne założenia i kładących nacisk na rozmaite czynniki istotne w integracji obcych wyrazów w języku docelowym. Modele te można zasadniczo podzielić na fonologiczne (np. Paradis, LaCharité 1997; Itô, Mester 1995), fonetyczne (lub percepcyjne) (np. Peperkamp i in. 2008; Boersma, Hamann 2009) oraz mieszane (np. Silverman 1992; Kang 2003). Pierwsze z nich utrzymują, że asymilacja zapożyczeń jest funkcją fonologicznej produkcji, drugie twierdzą, że proces ten zachodzi przede wszystkim na etapie percepcji, a trzecie dowodzą, że oba poziomy odgrywają w nim istotne role.

W niniejszym artykule zajmujemy się jednym z aspektów fonetyczno-fonologicznej integracji galicyzmów w języku polskim, mianowicie adaptacją akcentu wyrazowego. W związku z faktem, że akcent wyrazowy w języku francuskim jest oksytoniczny, a w języku polskim z reguły paroksytoniczny (z pewnymi wyjątkami), można zakładać, że w procesie asymilacji ulegnie on przesunięciu z ostatniej sylaby na przedostatnią ${ }^{1}$. Mimo że zmiana taka fak-

1 W niektórych przypadkach możliwe jest zachowanie oryginalnego miejsca akcentu, któremu towarzyszy dodanie sylaby, np. baguette $>$ bagiet $+k a$ (Bochnakowa 2012). 
tycznie ma miejsce w wielu przypadkach (np. champagne $>$ szampan), istnieje pewna grupa zapożyczeń z języka francuskiego, w których, mimo substytucji segmentalnej, akcent wyrazowy pozostaje na ostatniej sylabie (np. atelier).

Naszym głównym celem będzie zatem formalny opis współistnienia w ramach systemu fonologicznego języka polskiego galicyzmów z rozbieżnym akcentowaniem. Przedstawiona analiza zostanie sformułowana $\mathrm{w}$ ramach jednej z wersji teorii optymalności (Prince, Smolensky 1993/2004), zakładającej, że system fonologiczny języków naturalnych ma strukturę rdzeń-peryferie, w której tzw. ograniczenia wiernościowe (faithfulness constraints) są ruchome $\mathrm{w}$ stosunku do ograniczeń nacechowania (markedness constraints) (Itô, Mester 1995, 1999, 2001).

\section{Dane językowe}

Jak dowodzą liczne prace z zakresu fonetyczno-fonologicznej adaptacji zapożyczeń (np. Adler 2006; Itô, Mester 1995), wyrazy obce w różnym stopniu podlegają asymilacji, tj. dostosowaniu do systemu fonologicznego języka docelowego poprzez substytucję obcych głosek przez najbardziej podobne głoski języka biorcy ${ }^{2} . Z$ jednej strony wiele zapożyczeń podlega pełnej adaptacji fonetyczno-fonologicznej, np. anglicyzmy koktajl, brydż czy pikap, czemu często towarzyszy adaptacja graficzna, a także morfologiczna, ponieważ podlegają one regułom fleksyjnym języka polskiego oraz biorą udział w procesach słowotwórczych. Poniżej podajemy wybrane przykłady galicyzmów, które uległy całkowitej polonizacji na płaszczyźnie fonetyczno-fonologicznej, zarówno pod względem segmentalnym, jak i akcentu wyrazowego.

(1) Galicyzmy z akcentem paroksytonicznym (Bochnakowa 2012):

(a) galicyzmy, które zyskały dodatkową sylabę w procesie adaptacji allée > aleja baguette $>$ bagietka

tirade $>$ tyrada

2 W zależności od przyjętego modelu teoretycznego podobieństwo może być rozumiane w sposób fonologiczny, tj. jako bliskość pod względem fonologicznych cech dystynktywnych, lub fonetyczno-percepcyjny, tj. jako bliskość pod względem artykulacyjnym i/lub akustycznym. 
(b) galicyzmy, w których nastąpiło przesunięcie akcentu wyrazowego

$$
\begin{array}{ll}
\text { béchamel }>\text { beszamel } & \text { abat-jour }>\text { abażur } \\
\text { compote }>\text { kompot } & \text { mayonnaise }>\text { majonez } \\
\text { champagne }>\text { szampan } & \text { jeton }>\dot{z} \text { eton } \\
\text { voyage }>\text { wojaż } & \text { vernissage }>\text { wernisaż } \\
\text { contour }>\text { kontur } & \text { cornichon }>\text { korniszon } \\
\text { rondeau }>\text { rondo } &
\end{array}
$$

Z drugiej strony istnieje grupa zapożyczeń, które ulegają tylko częściowej adaptacji fonetyczno-fonologicznej, tj. są zgodne tylko z niektórymi zasadami fonologicznymi danego języka, a pewne z nich naruszają. Często wyrazy te są zapisywane $\mathrm{w}$ oryginalnej formie ortograficznej ${ }^{3}$, są nieodmienne i mogą funkcjonować jako tzw. cytaty z języka obcego (Bochnakowa 2012). W tej kategorii mieszczą się pewne zapożyczenia z języka francuskiego, które podlegają pełnej substytucji segmentalnej, ale zachowują francuski akcent oksytoniczny, tym samym naruszają reguły rządzące akcentem wyrazowym języka polskiego. Poniżej przedstawiamy wybrane przykłady.

(2) Galicyzmy z akcentem oksytonicznym (Bochnakowa 2012)

$\begin{array}{lll}\text { adieu } & \text { anchois } & \text { atelier } \\ \text { attaché } & \text { bordo/Bordeaux } & \text { bouclé } \\ \text { kamamber/camembert } & \text { cayenne } & \text { coupé } \\ \text { croissant } & \text { démodé } & \text { desu/dessous } \\ \text { dossier } & \text { ekrilécru } & \text { empire } \\ \text { emploi } & \text { entrée } & \text { exposé } \\ \text { fondue } & \text { foyer } & \text { frotté } \\ \text { jury } & \text { menu } & \text { merci } \\ \text { pardon } & \text { passé } & \text { pendant } \\ \text { pierrot } & \text { piure/purée } & \text { plateau } \\ \text { potpourri } & \text { résumé } & \text { sauté } \\ \text { tableau } & \text { tournée } & \text { voilà }\end{array}$

${ }^{3} \mathrm{~W}$ przypadku galicyzmów w języku polskim często pomijane są francuskie znaki diakrytyczne. 
Przedstawione dane językowe pokazują, że w ramach systemu fonologicznego języka polskiego współistnieją galicyzmy, których akcent wyrazowy został dostosowany do rodzimych reguł, oraz takie, które zachowały oryginalne miejsce akcentu z naruszeniem tychże reguł. Naszym celem będzie przedstawienie formalnego opisu tego zjawiska $\mathrm{w}$ ramach teorii optymalności oraz analiza fonologiczna zaobserwowanych rozbieżności w akcentowaniu.

\section{Komponent fonologiczny jako struktura rdzeń-peryferie}

W tej części zajmiemy się formalnym opisem danych językowych przedstawionych w części 2. Ponieważ nasza analiza jest ujęta w kategoriach teorii optymalności, zaczniemy od krótkiego przedstawienia podstawowych założeń tego modelu (3.1.), po czym przejdziemy do właściwej analizy materiału językowego (3.2.).

\subsection{Teoria optymalności}

W tradycyjnym derywacyjnym ujęciu generatywnym (Chomsky, Halle 1968), formy powierzchniowe języka są wynikiem działania uporządkowanych reguł fonologicznych, które przekształcają reprezentację bazową w strukturę powierzchniową. Teoria optymalności (Prince, Smolensky 1993/2004) to niederywacyjny model kompetencji językowej, którego głównym założeniem jest, że struktury powierzchniowe danego języka są wynikiem interakcji uniwersalnych ograniczeń (constraints). Istnieją dwa główne rodzaje ograniczeń, mianowicie ograniczenia nacechowania (markedness constraints) i ograniczenia wiernościowe (faithfulness constraints). Te pierwsze wyrażają preferencje wobec nienacechowanych struktur powierzchniowych i moga być formułowane w sposób negatywny lub pozytywny, np. „samogłoski nie mogą być nosowe” lub „sylaby muszą mieć nagłos” (Kager 1999: 9). Te drugie z kolei, wywierają nacisk na zachowanie kontrastu leksykalnego, tj. przeciwdziałają rozbieżnościom między strukturą bazową a strukturą powierzchniową, np. „segmenty wejściowe i segmenty powierzchniowe muszą mieć wspólną wartość cechy [dźwięczność]" (Kager 1999: 10). Podczas gdy ograniczenia nacechowania odnoszą się wyłącznie do form powierzchniowych, ograniczenia wiernościowe uwzględniają oba poziomy reprezentacji. 
Najważniejszymi właściwościami ograniczeń w teorii optymalności są ich uniwersalność i naruszalność. Pierwsza z nich odnosi się do założenia, że wszystkie języki posiadają ten sam zbiór ograniczeń, a wszelkie różnice międzyjęzykowe wynikają z różnic w ich hierarchii, które są specyficzne dla danego języka. Na przykład język z ubezdźwięcznieniem końcowym spółgłosek właściwych nadaje priorytet ograniczeniu nacechowania („spółgłoski właściwe nie mogą być dźwięczne na końcu wyrazu”) kosztem ograniczenia wiernościowego (,segmenty wejściowe i segmenty powierzchniowe muszą mieć wspólną wartość cechy [dźwięczność]”). Ranking, o którym mowa, jest odwrotny w języku, w którym istnieje kontrast dźwięczności spółgłosek właściwych na końcu wyrazu. Przykład ten pokazuje, że pewne pary ograniczeń nacechowania i wiernościowych stawiają sprzeczne wymagania, tak że przestrzeganie jednego z nich pociąga za sobą pogwałcenie drugiego. Ograniczenia w teorii optymalności są zatem naruszalne, jednak naruszenie musi być minimalne i dochodzi do niego tylko wtedy, gdy istnieje konieczność uniknięcia naruszenia jakiegoś ograniczenia lub ograniczeń o wyższej randze. W rezultacie fakt, że dana forma powierzchniowa narusza pewne ograniczenia, nie prowadzi automatycznie do jej niepoprawności.

Podstawowe komponenty językowe w teorii optymalności obejmują Leksykon, Generator (GEN) i Ewaluator (EVAL). Leksykon zawiera zbiór reprezentacji bazowych, które stanowią formy wejściowe. Ponieważ teoria optymalności nie zakłada żadnych ograniczeń struktury morfemu podobnych do tych proponowanych w klasycznej fonologii generatywnej, nie istnieją żadne specyficzne dla danego języka ograniczenia form wejściowych (jest to tzw. zasada Richness of the Base). Dane wejściowe z Leksykonu są przekazywane do Generatora (GEN), którego funkcją jest generowanie zbioru potencjalnych form wyjściowych, tzw. kandydatów, dla określonej formy wejściowej. Zbiór ten zawiera wszystkie logicznie możliwe realizacje formy wejściowej i jest zasadniczo nieskończony. Kandydaci wygenerowani przez GEN są następnie poddawani ocenie Ewaluatora (EVAL). Jego centralnym składnikiem jest tzw. Con, który obejmuje hierarchię uniwersalnych ograniczeń w danym języku. Funkcja EVAL polega na selekcji tzw. optymalnej formy spośród kandydatów wygenerowanych przez GEN.

W klasycznej wersji teorii optymalności każdy język posiada jeden, niezmienny ranking uniwersalnych ograniczeń. Należy jednak zauważyć, że chociaż podstawowy mechanizm teorii optymalności, tj. interakcja ograniczeń, 
pozostał niezmieniony od momentu powstania teorii na początku lat 90 . XX wieku, niektóre z jej założeń były kwestionowane, w wyniku czego wyłoniło się wiele jej wersji. Jedną z nich jest model rdzeń-peryferie zaproponowany przez Itô i Mestera $(1995,1999,2001)$, których analiza stratyfikacji leksykalnej w języku japońskim oparta jest na założeniu, że systemy fonologiczne języków naturalnych są zorganizowane w strukturę rdzeń-peryferie. Innymi słowy, składają się one z kilku warstw skoncentrowanych wokół nienacechowanego rdzenia, w którym przestrzegane są wszystkie ograniczenia fonologiczne danego języka. Wyrazy znajdujące się w warstwach peryferyjnych przestrzegają coraz mniej ograniczeń, przy czym niektóre spełniają jedynie podstawowe wymagania, np. dotyczące struktury sylaby. Rdzeń obejmuje słownictwo rodzime oraz w pełni zasymilowane zapożyczenia, podczas gdy warstwy peryferyjne zawierają między innymi onomatopeje, a także zapożyczenia o różnym stopniu adaptacji.

\subsection{Analiza fonologiczna akcentu wyrazowego $w$ galicyzmach w języku polskim}

Poniższa analiza fonologiczna akcentu wyrazowego w galicyzmach w polszczyźnie opiera się na założeniu wywiedzionym z prac Itô i Mestera (1995, 1999, 2001), zgodnie z którym systemy fonologiczne języków naturalnych mają strukturę rdzeń-peryferie. W kategoriach teorii optymalności oznacza to, że wyrazy należące do rdzenia przestrzegają wszystkich ograniczeń fonologicznych danego języka, natomiast elementy peryferyjne są zgodne tylko z pewnym podzbiorem tych ograniczeń. W omawianym przypadku możemy zatem przyporządkować w pełni zasymilowane galicyzmy z akcentem paroksytonicznym do rdzenia, natomiast te częściowo spolonizowane $\mathrm{z}$ akcentem oksytonicznym do warstwy peryferyjnej.

W procesie fonetyczno-fonologicznej asymilacji zapożyczeń zachodzi konflikt między dostosowaniem obcych struktur dźwiękowych do reguł języka docelowego z jednej strony oraz jak najwierniejszym odtworzeniem oryginału z drugiej. W teorii optymalności sytuację taką można formalnie ująć jako konflikt pomiędzy ograniczeniami nacechowania, które dążą do modyfikacji obcych struktur zgodnie z zasadami języka biorcy, a ograniczeniami wiernościowymi, które wywierają presję w kierunku minimalizacji 
kontrastu pomiędzy reprezentacją wejściową a wyjściową. W omawianym przypadku możemy zaobserwować działanie następujących ograniczeń:

(3) Ograniczenia fonologiczne istotne w adaptacji akcentu wyrazowego:

a) ograniczenie nacechowania

PENULT: akcent wyrazowy jest paroksytoniczny (tj. pada na przedostatnią sylabę wyrazu) (Guest $i$ in. 2000)

b) ograniczenie wiernościowe

IDENT(stress): akcent wyrazowy w reprezentacji bazowej i reprezentacji powierzchniowej pada na tę samą sylabę (McCarthy, Prince 1995)

Rezultat asymilacji galicyzmów w polszczyźnie w zakresie akcentu wyrazowego zależy od wzajemnego usytuowania wyżej wymienionych ograniczeń w rankingu. Jeżeli PENULT dominuje nad IDENT(stress), akcent wyrazowy w formie powierzchniowej jest paroksytoniczny, niezależnie od miejsca akcentu w formie wyjściowej, co ilustruje tabela $1^{4}$.

Tabela 1. Zmiana akcentu z oksytonicznego na paroksytoniczny (champagne $>$ szampan)

\begin{tabular}{|c|c|c|}
\hline cham.'pagne & PENULT & IDENT(stress) \\
\hline 'szam.pan & & $*$ \\
\hline szam.'pan & $* !$ & \\
\hline
\end{tabular}

Źródło: opracowanie własne.

Przy rankingu PENULT >> IDENT(stress) forma $\mathrm{z}$ akcentem oksytonicznym zostaje odrzucona ze względu na naruszenie ograniczenia PENULT, które ma wyższą rangę niż IDENT(stress). W rezultacie forma $\mathrm{z}$ akcentem paroksytonicznym zostaje wybrana jako optymalna pomimo naruszenia ograniczenia IDENT(stress). W związku z tym, że akcent wyrazowy w języku pol-

${ }^{4}$ Ponieważ nasza dyskusja koncentruje się na kwestii adaptacji akcentu wyrazowego, dla jasności wywodu pomijamy w tabelach kwestie asymilacji segmentalnej. W tabelach stosowane są następujące symbole: - forma optymalna; ' - akcent wyrazowy; * - naruszenie ograniczenia; *! - naruszenie ograniczenia, które eliminuje daną formę. 
skim jest zasadniczo paroksytoniczny, hierarchia ograniczeń przedstawiona w tabeli 1 obowiązuje w rdzeniu polskiego systemu fonologicznego.

Jeżeli ranking jest odwrotny, akcent wyrazowy w reprezentacji powierzchniowej pada na tę samą sylabę, co w formie wyjściowej (tabela 2).

Tabela 2. Zachowanie akcentu oksytonicznego (atelier)

\begin{tabular}{|c|c|c|}
\hline a.te.'lier & IDENT(stress) & PENULT \\
\hline a.'te.lier & $* !$ & $*$ \\
\hline a.te.'lier & & \\
\hline
\end{tabular}

Źródło: opracowanie własne.

Przy rankingu IDENT(stress) $\gg$ PENULT forma $\mathrm{z}$ akcentem paroksytonicznym zostaje odrzucona ze względu na naruszenie ograniczenia IDENT(stress), które ma wyższą rangę niż PENULT. W rezultacie forma $\mathrm{z}$ akcentem oksytonicznym zostaje wybrana jako optymalna pomimo naruszenia ograniczenia PENULT. Ranking przedstawiony w tabeli 2, w którym IDENT(stress) ma wyższą pozycję w stosunku do PENULT niż w tabeli 1, jest rankingiem obowiązującym w sferze peryferyjnej polskiego systemu fonologicznego, ponieważ daje on wyniki naruszające ogólną zasadę akcentowania w języku polskim.

W omawianym przypadku przyjęcie klasycznej wersji teorii optymalności, zgodnie z którą każdy język ma jeden, niezmienny ranking uniwersalnych ograniczeń, prowadziłoby do problemu sprzecznych rankingów. Aby wyjaśnić rozbieżności w akcentowaniu galicyzmów, uzasadnione zatem wydaje się założenie, że zapożyczenia $\mathrm{z}$ akcentem paroksytonicznym należą do rdzenia systemu fonologicznego języka polskiego, a te $\mathrm{z}$ akcentem oksytonicznym do jego peryferii. Rdzeń i peryferie różnią się od siebie pod względem obowiązujących w nich hierarchii ograniczeń. Wraz z oddalaniem się od nienacechowanego rdzenia, niektóre ograniczenia nacechowania mogą zostać zdezaktywowane poprzez promocję w rankingu ograniczeń wiernościowych. Innymi słowy, im dalej od rodzimego rdzenia, tym większa rola ograniczeń wiernościowych kosztem ograniczeń nacechowania, a tym samym częstsze występowanie obcych struktur dźwiękowych. 
Warto również zaznaczyć, że przyjęta przez nas struktura rdzeń-peryferie pozwala wyjaśnić istnienie niektórych innych grup wyrazów w polszczyźnie, których akcent nie jest paroksytoniczny. Na przykład do sfery peryferyjnej można przyporządkować wykrzykniki i onomatopeje, takie jak Ojej!, Acha! czy Łubudu!, które są zwykle akcentowane na ostatnią sylabę, oraz zapożyczenia z greki lub łaciny, takie jak matematyka, fizyka czy logika, $\mathrm{z}$ akcentem proparoksytonicznym. W przypadku tych drugich często można jednak zaobserwować akcent paroksytoniczny, co stanowi naruszenie powyższej normy, ale jest zgodne z ogólną regułą akcentowania w języku polskim. W kategoriach rdzenia i peryferii taka sytuacja świadczy o tym, że zapożyczenia te często nie są już traktowane jako wyrazy obce, a tym samym nastąpiło ich przejście ze sfery peryferyjnej do rdzenia. Przyjęte przez nas podejście umożliwia również analizę innych zjawisk fonologicznych, w przypadku których mamy do czynienia z odstępstwami od ogólnych reguł rządzących systemem dźwiękowym polszczyzny, np. rzadkich grup spółgłoskowych w toponimach (Jaskuła, Szpyra-Kozłowska, w druku). Staną się one przedmiotem kolejnych artykułów.

\section{Podsumowanie}

W niniejszym artykule zajęliśmy się kwestią adaptacji akcentu wyrazowego w zapożyczeniach z języka francuskiego w polszczyźnie. Przedstawione dane językowe wykazały, że w ramach systemu fonologicznego języka polskiego współistnieją galicyzmy, których akcent jest paroksytoniczny, a więc zgodny z rodzimymi regułami, oraz takie, które zachowały oryginalny akcent, $\mathrm{tj}$. oksytoniczny, z naruszeniem tychże reguł. Zaproponowana formalna analiza tego zjawiska $\mathrm{w}$ ramach teorii optymalności opiera się na założeniu wywiedzionym z prac Itô i Mestera (1995, 1999, 2001), zgodnie z którym systemy fonologiczne języków naturalnych mają strukturę rdzeń-peryferie. Galicyzmy z akcentem paroksytonicznym zostały przyporządkowane do rdzenia, natomiast te $\mathrm{z}$ akcentem oksytonicznym do sfery peryferyjnej. W każdej z tych warstw obowiązują odmienne rankingi ograniczeń fonologicznych, czego wynikiem jest rozbieżność akcentowania w obu grupach zapożyczeń. Przyjęte podejście może umożliwić również wyjaśnienie innych zjawisk fonologicznych, np. akcentu oksytonicznego w skrótowcach oraz rzadkich grup spółgłoskowych w toponimach. 


\section{Bibliografia}

Adler A. N., 2006, Faithfulness and perception in loanword adaptation: a case study from Hawaiian, Lingua 116, s. 1024-1045, [online:] https://doi.org/10.1016/ j.lingua.2005.06.007.

Bochnakowa A., 2009, O najnowszych galicyzmach, Język Polski LXXXIX/1, s. 53-54.

Bochnakowa A. (red.), 2012, Wyrazy francuskiego pochodzenia we wspótczesnym języku polskim, Kraków: Wydawnictwo Uniwersytetu Jagiellońskiego.

Boersma P., Hamann S., 2009, Loanword adaptation as first-language phonological perception, w: A. Calabrese, L. W. Wetzels (red.), Loan Phonology, Amsterdam \& Philadelphia: John Benjamins, s. 11-58.

Borys I., 2000, Aktualne zapożyczenia francuskie we współczesnym słownictwie polskim i rosyjskim: rzeczowniki, Acta Polono-Ruthenica 5, s. 209-217.

Chomsky N., Halle M., 1968, The sound pattern of English, New York: Harper \& Row.

Guest D. J., Dell G. S., Cole J. S., 2000, Violable constraints in language production: testing the transitivity assumption of Optimality Theory, Journal of Memory and Language 42, s. 272-299, [online:] https://doi.org/10.1006/jmla.1999.2679.

Itô J., Mester A., 1995, Japanese phonology, w: J. A. Goldsmith (red.), The handbook of phonological theory, Oxford: Blackwell, s. 817-838.

Itô J., Mester A., 1999, The phonological lexicon, w: N. Tsujimura (red.), The handbook of Japanese linguistics, Oxford: Blackwell, s. 62-100.

Itô J., Mester A., 2001, Covert generalizations in Optimality Theory: the role of stratal faithfulness constraints, Studies in Phonetics, Phonology, and Morphology 7, s. 273-299.

Kager R., 1999, Optimality Theory, Cambridge: Cambridge University Press, [online:] https://doi.org/10.1017/S0952675700001627.

KANG Y., 2003, Perceptual similarity in loanword adaptation: adaptation of English post-vocalic word-final stops in Korean, Phonology 20, s. 219-273, [online:] https://doi.org/10.1017/S0952675703004524.

McCarthy J., Prince A., 1995, Faithfulness and reduplicative identity, University of Massachusetts Occasional Papers 18, s. 249-384.

Paradis C., LaCharité D., 1997, Preservation and minimality in loanword adaptation, Journal of Linguistics 33, s. 379-430, [online:] https://doi.org/ 10.1017/ S0022226797006786.

Peperkamp S., Vendelin I., NaKamura K., 2008, On the perceptual origin of loanword adaptations: experimental evidence from Japanese, Phonology 25, s. 129 -164, [online:] https://doi.org/10.1017/S0952675708001425. 
Porayski-Pomsta J., 2007, Zapożyczenia leksykalne z języka francuskiego we współczesnej polszczyźnie: charakterystyka strukturalno-semantyczna, Poradnik Językowy 5, s. 54-65.

PoRAYski-Pomsta J., 2011, Zakresy (pola) tematyczne zapożyczeń leksykalnych z języka francuskiego w polszczyźnie, Poradnik Językowy 4, s. 5-25.

Prince A., Smolensky P., [1993] 2004, Optimality Theory: constraint interaction in generative grammar, Oxford: Blackwell.

Radomski M., 2019, Polish consonant clusters in the British mouth. A study in online loanword adaptation, Berlin: Peter Lang.

RYBICKA H., 1989, Zapożyczenia francuskie w języku polskim i rosyjskim w aspekcie socjolingwistycznym, Studia z Filologii Rosyjskiej i Słowiańskiej 17, s. 65-73.

Silverman D., 1992, Multiple scansions in loanword phonology: evidence from Cantonese, Phonology 9, s. 289-328, [online:] https://doi.org/10.1017/ S0952 675700001627.

SzPyra-KozıowsKa J., 2016a, Pozajęzykowe czynniki kształtujące fonetyczną i fonologiczną adaptację anglicyzmów we współczesnej polszczyźnie, Poradnik Językowy, 2, s. 21-37.

SzPyra-KozŁowsKa J., 2016b, Wewnątrzjęzykowe mechanizmy fonologicznej polonizacji zapożyczeń angielskich, Poradnik Językowy, 6, s. 61-76.

SyPNiCKi J., 1983, O wpływie języka francuskiego na tworzenie złożonych jednostek leksykalnych języka polskiego, Sprawozdania Poznańskiego Towarzystwa Przyjaciół Nauk 97-99, s. 198-200.

Tombińska A., 1998, Z zagadnień semantyki galicyzmów, Polonica 14, s. 143-155.

WALCZAK B., 1992a, Najnowsze (powojenne) zapożyczenia francuskie w języku polskim, w: E. Homa (red.), Z badań nad współczesna polszczyzna, Szczecin: Wydawnictwo Uniwersytetu Szczecińskiego, s. 97-109.

WALCZAK B., 1992b, Produktywność galicyzmów jako podstaw słowotwórczych współczynnik rozwoju leksykalnego języka polskiego i rosyjskiego, w: J. Zieniukowa (red.), Procesy rozwojowe w językach słowiańskich, Warszawa: Slawistyczny Ośrodek Wydawniczy, s. 189-197. 
The phonological component of Polish as a core-periphery structure - evidence from word stress in gallicisms

\section{( su m mary)}

The article deals with word stress adaptation in French loanwords in Polish. The presented data demonstrate that the borrowings in question can be divided into two categories in terms of stress placement. On the one hand, there are items with penultimate stress, which conform to native Polish stress rules. On the other hand, there are those which retain the original final stress in violation of these rules. The proposed formal analysis of this phenomenon within Optimality Theory is based on the assumption derived from Itô and Mester $(1995,1999,2001)$ that phonological systems of natural languages have a core-periphery structure. The gallicisms with penultimate stress have thus been assigned to the core, while those with final stress to the periphery. It is argued that each stratum has a different constraint ranking, which results in the divergent adaptation of word stress.

Ke y w or d s : gallicisms; loanword phonology; word stress; Optimality Theory 
